\title{
Identification of Responsible Variables for Obesity Hypertension among Bangladeshi Adults
}

\author{
K.C.Bhuyan*
}

*Department of Statistics, Jahangirnagar University, Dhaka, Bangladesh.

*Corresponding Author: K.C.Bhuyan, Department of Statistics, Jahangirnagar University, Dhaka, Bangladesh.

\section{Abstract}

The results presented here were derived using the data collected from 960 adults of Bangladesh. These adults were of ages 18 years and above and they were the residents of both urban and rural localities. Out of 960 respondents, 86 were found obese and hypertensive. The objective of the study was to detect the influencing socioeconomic factors for obesity and hypertension and to identify the most responsible variable for this health hazard. It was evident that sex, occupation, sedentary activity and marital differential, were the significant social determinants for the prevalence of obesity and hypertension simultaneously. The problem of this health hazard was more likely to develop in subjects like non-Muslim, female, adult of ages 40 -50 years, illiterate, rich, higher expenditure group of families, and physically inactive compared to subjects with other levels of these socioeconomic variables. Factor analysis was done to identify the most responsible variables for the prevalence of obesity hypertension in adults. The analysis indicated that sedentary activity was the most responsible factor for this health problem followed by age, duration of disease, being married and physical inactivity.

Keywords : Obesity, Hypertension, Association, Coefficient of association, Odds ratio (O.R.), Standard error of $\ln (O . R$.$) , Factor analysis.$

\section{INTRODUCTION}

Obesity is one of the most risk factors for the development of hypertension and both these health hazard are recognized as public health challenges [1, 2]. This problem is in increasing trend worldwide. The number of adults with hypertension will be increasing by approximately $60 \%$ to a total of 1.56 billion in 2025 in comparison with 2000 [1]. Again, obesity is the risk factor not only for hypertension but also for diabetes [2]. Hypertension prevailed in around 30 $\%$ patients of type 1 diabetes and $50-60 \%$ patients of type 2 diabetes [3]. In separate studies, it was reported that diabetes had a role in the development of hypertension, specially type 2 diabetes around 2.5 times likely to develop in patients with hypertension compared to subjects having normal blood pressure $[4,5]$.

Simultaneous occurrence of obesity and hypertension in the same individual doubles the risk of cardiovascular deaths [ 6 ]. Obesity and its associated cardiovascular and renal disorders are major threat to global health [7]. The problem is nearly doubled since 1980 and tripled since 1975 [ 8 ].
The prevalence of obesity was increasing in many countries, specially in developing countries due to socio-demographic upward mobility despite continuing nutritional deficiencies [ 7,8 ]. In developed countries the problem of obesity has been increasing rapidly [7-11]. In 2016, the reported overweight adults of age 18 years and above were 1.9 billon and obese adults were 650 million [ 12 ]. The burden of obesity was shifting towards lower socioeconomic group of people.

The above information indicates that the epidemic of obesity and obesity related hypertension is paralleled by an alarming increase in the incidence of cardiovascular disease, renal disease and kidney disease. Some socioeconomic variables were found associated with these diseases as was observed in both home and abroad [ 13 - 24]. Thus, it was decided to investigate the association of prevalence of obesity hypertension with different socioeconomic variables and to identify the more responsible variables for this health hazard. 
Identification of Responsible Variables for Obesity Hypertension among Bangladeshi Adults

\section{METHODOLOGY}

The sample adults were investigated by quota sampling plan to cover $70 \%$ diabetic patients

[13] so that sufficient number of obese and hypertensive adults would be included in the sample. During investigation data were recorded from $66.9 \%$ diabetic and $33.1 \%$ normal subjects to a total of 960 adults of ages 18 years and above. They were investigated by some doctors and nurses from and nearby their working places during the academic session 2017 - 18 by direct interview. Data were recorded from respondents through a pre-designed and pre-tested questionnaire. Maximum questions in the questionnaire were related to different socioeconomic variables of the respondents and of the families. Except two information, viz. monthly family income and monthly family expenditure, all other questions were related to different socioeconomic variables of the respondents and of their personal habit, viz. food habit, working habit, physical activity, utilization of time, etc. For diabetic patients there were questions related to duration of disease, disease related health hazard, i.e. eye problem, kidney problem, heart problem, blood pressure, blood sugar, treatment stage of disease, admission into hospital, etc. The value of each of the variable was noted in nominal scale. The data of weight

( in $\mathrm{kg}$ ) divided by Height ( in metre ${ }^{2}$ ) was used to measure the value of body mass index (BMI) to identify obese adults( if BMI $\geq 30$ ).

According to the objective of the study, association of any of the socioeconomic characteristics with prevalence of obesity hypertension was examined. The prevalence of obesity hypertension of any respondent was decided if diastolic blood pressure $\geq 85 \mathrm{mmHg}$ and BMI $\geq 30$ for him/her. Significant association was decided if probability of any Chi-square test statistic used for observing association $\leq 0.05$. Irrespective of significant or insignificant association, the odds ratio [O.R ] in favour of a higher group ( in percentage) of obese and hypertensive adults along with standard error of $\ln (\mathrm{O} . \mathrm{R})$ was calculated. Finally, factor analysis
[ 25 - 27 ] was done to identify the most responsible variable for the prevalence of obesity hypertension among adults. The most responsible variable was detected according to the value of highest factor loading. All the statistical results were calculated using SPSS [ Version 25].

\section{RESULTS}

The prevalence of obesity hypertension was observed among 86(9\%) adults out of 960 respondents. Total obese and hypertensive adults were $92(9.6 \%)$ and 145 (15.1\%), respectively in the sample. Among obese adults

Table 1. Distribution of adults according to prevalence of obesity and hypertension.

\begin{tabular}{|c|c|c|c|}
\hline \multirow{2}{*}{$\begin{array}{c}\text { Prevalence } \\
\text { of Obesity }\end{array}$} & \multicolumn{2}{|c|}{$\begin{array}{c}\text { Prevalence of } \\
\text { hypertension }\end{array}$} & \multirow{2}{*}{ Total } \\
\cline { 2 - 3 } & Yes & No & \\
\hline Yes & 86 & 6 & 92 \\
\hline No & 59 & 809 & 868 \\
\hline Total & 145 & 815 & 960 \\
\hline
\end{tabular}

$93.5 \%$ were hypertensive as against $6.8 \%$ non-obese hypertensive. This differentials in the distribution of adults of different categories were highly significant $\left[\chi^{2}=48.42\right.$, $p$-value $\left.=0.000\right]$.

Percentage of urban adults was 56.5 and $9.0 \%$ of them were obese and hypertensive at the same time against $8.9 \%$ of the same group from rural area. This differential in percentages of obese hypertensive adults in urban and rural localities was not significant $\left[\chi^{2}=0.010\right.$, $p$-value $\left.=0.919\right]$. Rural and urban adults were similarly exposed to this health hazard [O.R.=1.02; s.e(lnO.R. $)=0.23]$. Obesity hypertension was 2.5 times [ $0 . R .=2.5$; s.e.(lnO.R.) $=0.24$ ] likely to develop in female ( $44.8 \%$ ) subjects as in male subjects (55.2\%). The problem prevailed among $13 \%$ female subjects as against $5.7 \%$ male subjects. The gender variation of obesity hypertension was significant $\left[\chi^{2}=15.780\right.$,pvalue $=0.000]$. The coefficient of association between gender and prevalence of obesity hypertension was 0.127.There was no significant association between religion and prevalence of obesity hypertension Table2. Distribution of adults according to prevalence of obesity hypertension and socioeconomic variables

\begin{tabular}{|l|c|c|c|c|c|c|}
\hline \multirow{2}{*}{ Socioeconomic variables } & \multicolumn{3}{|c|}{ Prevalence of obesity hypertension } & \multicolumn{2}{|c|}{ Total } \\
\cline { 2 - 7 } & \multicolumn{2}{|c|}{ Yes } & \multicolumn{2}{|c|}{ No } & \multicolumn{2}{c|}{} \\
\cline { 2 - 7 } & $\mathrm{n}$ & $\%$ & $\mathrm{n}$ & $\%$ & $\mathrm{n}$ & $\%$ \\
\hline Residence & & & & & & \\
\hline
\end{tabular}


Identification of Responsible Variables for Obesity Hypertension among Bangladeshi Adults

\begin{tabular}{|c|c|c|c|c|c|c|}
\hline Rural & 37 & 8.9 & 381 & 91.1 & 418 & 43.5 \\
\hline Urban & 49 & 9.0 & 493 & 91.0 & 542 & 56.5 \\
\hline Total & 86 & 9.0 & 874 & 91.0 & 960 & 100.0 \\
\hline \multicolumn{7}{|l|}{ Gender } \\
\hline Male & 30 & 5.7 & 500 & 94.3 & 530 & 55.2 \\
\hline Female & 56 & 13.0 & 374 & 87.0 & 430 & 44.8 \\
\hline \multicolumn{7}{|l|}{ Religion } \\
\hline Muslim & 68 & 8.6 & 725 & 91.4 & 793 & 82.6 \\
\hline Non-Muslim & 18 & 10.8 & 149 & 89.2 & 167 & 17.4 \\
\hline \multicolumn{7}{|l|}{ Marital status } \\
\hline Currently married & 68 & 10.1 & 602 & 89.9 & 670 & 69.8 \\
\hline Currently single & 18 & 6.2 & 272 & 93.8 & 290 & 30.2 \\
\hline \multicolumn{7}{|l|}{ Age ( in years) } \\
\hline$<20$ & 3 & 10.7 & 25 & 89.3 & 28 & 2.9 \\
\hline $20-30$ & 10 & 6.2 & 152 & 93.8 & 162 & 16.9 \\
\hline $30-40$ & 16 & 6.4 & 234 & 93.6 & 250 & 26.0 \\
\hline $40-50$ & 34 & 12.9 & 230 & 87.1 & 264 & 27.5 \\
\hline $50^{+}$ & 23 & 9.0 & 223 & 91.0 & 256 & 26.7 \\
\hline \multicolumn{7}{|l|}{ Education } \\
\hline Illiterate & 7 & 13.0 & 47 & 87.0 & 54 & 5.6 \\
\hline Primary & 6 & 5.2 & 109 & 94.8 & 115 & 12.0 \\
\hline Secondary & 23 & 10.0 & 206 & 90.0 & 229 & 23.9 \\
\hline Higher & 50 & 8.9 & 512 & 91.1 & 562 & 58.5 \\
\hline \multicolumn{7}{|l|}{ Occupation } \\
\hline Agriculture and unskilled labor & 16 & 6.3 & 239 & 93.7 & 255 & 26.6 \\
\hline Business and skilled labor & 15 & 9.3 & 146 & 90.7 & 161 & 16.8 \\
\hline Service & 14 & 6.6 & 199 & 93.4 & 213 & 22.2 \\
\hline Housewives,students and unemployed & 41 & 12.4 & 290 & 87.6 & 331 & 34.5 \\
\hline \multicolumn{7}{|l|}{ Income ( in 000 taka) } \\
\hline$<40$ & 27 & 8.7 & 284 & 91.3 & 311 & 32.4 \\
\hline $40-60$ & 12 & 6.3 & 177 & 93.7 & 189 & 19.7 \\
\hline $60-80$ & 16 & 8.5 & 172 & 91.5 & 188 & 19.6 \\
\hline $80-100$ & 14 & 8.8 & 146 & 91.2 & 160 & 16.7 \\
\hline $100^{+}$ & 17 & 15.2 & 95 & 84.8 & 112 & 11.7 \\
\hline \multicolumn{7}{|l|}{ Smoking habit } \\
\hline Yes & 25 & 6.7 & 348 & 93.3 & 373 & 38.9 \\
\hline No & 61 & 10.4 & 526 & 89.6 & 587 & 61.1 \\
\hline \multicolumn{7}{|l|}{ Family expenditure ( in 000 taka) } \\
\hline$<30$ & 11 & 9.5 & 105 & 90.5 & 116 & 12.1 \\
\hline $30-50$ & 22 & 7.5 & 273 & 92.5 & 295 & 30.7 \\
\hline $50-70$ & 18 & 8.7 & 190 & 91.3 & 208 & 21.7 \\
\hline $70-90$ & 17 & 9.6 & 160 & 90.4 & 177 & 18.4 \\
\hline $90^{+}$ & 18 & 11.0 & 146 & 89.0 & 164 & 17.1 \\
\hline \multicolumn{7}{|l|}{ Taking restaurant food } \\
\hline Yes & 52 & 10.5 & 441 & 89.5 & 493 & 51.4 \\
\hline
\end{tabular}

Archives of Diabetes and Endocrine System V3 . I1 . 2020 
Identification of Responsible Variables for Obesity Hypertension among Bangladeshi Adults

\begin{tabular}{|l|l|l|l|l|l|l|}
\hline \hline No & 34 & 7.3 & 433 & 92.7 & 467 & 48.6 \\
\hline Use of can food & & & & & & \\
\hline Yes & 48 & 8.2 & 536 & 91.8 & 584 & 60.8 \\
\hline No & 38 & 10.1 & 338 & 89.9 & 376 & 39.2 \\
\hline Physical work & & & & & & \\
\hline Yes & 26 & 7.4 & 325 & 92.6 & 351 & 36.6 \\
\hline No & 60 & 9.9 & 549 & 90.1 & 609 & 63.4 \\
\hline Utilization of time & & & & & & \\
\hline Read and use mobile phone & 14 & 10.1 & 125 & 89.9 & 139 & 14.5 \\
\hline Play and use mobile phone & 7 & 2.9 & 234 & 97.1 & 241 & 25.1 \\
\hline Do household work and watch T.V. & 28 & 11.3 & 219 & 88.7 & 247 & 25.7 \\
\hline $\begin{array}{l}\text { Read paper and use mobile phone after } \\
\text { office work }\end{array}$ & 15 & 6.0 & 234 & 94.0 & 249 & 25.9 \\
\hline $\begin{array}{l}\text { Watch T.V. and use mobile phone after } \\
\text { office work }\end{array}$ & 22 & 26.2 & 62 & 3.8 & 84 & 8.8 \\
\hline Prevalence of diabetes & & & & & & \\
\hline Yes & 40 & 6.2 & 602 & 93.8 & 642 & 66.8 \\
\hline No & 46 & 14.5 & 272 & 85.5 & 318 & 33.2 \\
\hline Total & 86 & 9.0 & 874 & 91.0 & 960 & 100.0 \\
\hline
\end{tabular}

$\left[\chi^{2}=0.821 \mathrm{p}\right.$-value $\left.=0.365\right]$. still, non-Muslim adults were $29 \%$ more exposed to this health hazard [O.R. $=1.29$, s.e.(lnO.R.)=0.28]. The coefficient of association between religion and prevalence of obesity hypertension was 0.029 . Out of $69.8 \%$ married adults $10.1 \%$ had the experience of obesity hypertension and this health hazard was 1.71 times likely to develop to married subjects as in unmarried subjects [ $0 . R .=1.71$, s.e.(lnO.R.) $=0.27]$. There was significant association between marital status and prevalence of this health hazard $\left[\chi^{2}=3.857, \mathrm{p}\right.$-value $=0.050$; coefficient of association $=0.063 \mathrm{]}$. Obesity and hypertension was almost 1.83 times likely to develop in adults of ages $40-50$ years as in adults of other ages [ O.R. $=1.87$, s.e.(lnO.R.) $=0.023$ ]. Percentage of affected adults of this group was 12.9. The corresponding percentage was 10.7 among adults of ages less than 20 years. Though there was no significant association between age and this health hazard $\left[\chi^{2}=8.629\right.$, $p$-value $=0.071$; coefficient of association $=0.127]$.

Level of education and prevalence of obesity hypertension was not significantly associated $\left[\chi^{2}=3.368\right.$, $\mathrm{p}$-value $=0.338$; coefficient of association $=$ 0.059]. But illiterate adults were $56 \%$ more exposed to this health problem compared to adults of other level of education [O.R. $=1.56$, s.e.(lnO.R. $=0.42]$. Percentage of illiterate adults facing this problem was

13.0 followed by secondary level educated persons (10.0\%).

Most of the adults ( $63.4 \%$ ) were not doing any physical work and they were $37 \%$ more exposed to this health problem compared to their counterpart [ O.R. $=1.37$, s.e(lnO.R. $)=0.28]$. However, there was no significant association between prevalence of obesity hypertension and physical work $\left[\chi^{2}=1.632\right.$, $\mathrm{p}$-value $=0.201$; coefficient of association $=0.041]$. Housewives, students and unemployed adults were not rendering physical labour directly [28] and they were expectedly $83 \%$ more exposed to this health hazard [ $0 . R .=1.83$, s.e $(\ln 0 . R)=0.23]$. In the sample they were $34.5 \%$ and prevalence of the problem was noted among $12.4 \%$ of them. Level of occupation was significantly associated with prevalence of obesity hypertension $\left[\chi^{2}=8.534\right.$, p-value $=0.036$; coefficient of association $=0.094]$.

Percentage of adults from highest income group of families was 11.7 and $15.2 \%$ of them were facing this health problem. This group of respondents was almost two times exposed to this problem compared to that of other adults [ $0 . R .=2.02$, s.e $(\ln 0 . R)=0.29]$. But family income was not significantly associated with prevalence of obesity hypertension $\left[\chi^{2}=6.975\right.$, $\mathrm{p}$-value $=0.137]$. Similar was the case with family 
Identification of Responsible Variables for Obesity Hypertension among Bangladeshi Adults

expenditure $\left[\chi^{2}=1.786, \mathrm{p}\right.$-value $=0.775$; coefficient of association $=0.043$ ]. But adults $(17.1 \%)$ of highest expenditure group of families was 32\% more exposed to this health hazard in comparison with that of adults of other families [ O.R. $=1.32$, s.e (lnO.R.) $=0.28$ ].

Percentage of adults accustomed with restaurant food was 51.4 and prevalence of obesity hypertension was 1.5 times likely in them as it was in adults not taking restaurant food [ O.R.= 1.50, s.e.(ln O.R.) = 0.23]. However, insignificant association between habit of taking restaurant food and prevalence of obesity hypertension was noted $\left[\chi^{2}=3.139\right.$,p-value $=0.076$; coefficient of association $=0.057$ ]. A big group of adults ( $60.8 \%$ ) were habituated in using can food , but $8.2 \%$ of them were experienced of obesity hypertension. Use of can food was not influencing factor in enhancing the rate of obesity and hypertension simultaneously in adults [ $\chi^{2}=0.999, \mathrm{p}$-value $=0.318$; coefficient of association $=0.032]$. Similar was the case with smoker and non-smoker respondents $\left[\chi^{2}=3.653, \mathrm{p}\right.$ -value $=0.056$; coefficient of association $=0.062]$. But non-smokers were $60 \%$ more exposed to the problem [ O.R. $=1.60$, s.e $(\ln 0 . R)=0.25]$.

In the sample $34.7 \%$ adults were involved in sedentary activities, like passing their time by reading paper, watching T.V. and gossiping with friends through mobile phone after their normal duties and 11.4\% of them were experienced of obesity hypertension as against $9.0 \%$ adults of this category in the sample. This health hazard was almost 4.5 times likely to develop in these adults as in adults with normal activities [O.R.
$=4.56$, s.e (ln O.R.) = 0.28]. Significant association between utilization of time and obesity hypertension was noted $\left[\chi^{2}=45.965\right.$, $\mathrm{p}$ - value $=0.000$; coefficient of association $=0.057$ ].

\section{FACTOR ANALYSIS}

In investigating the association between prevalence of obesity hypertension and each of socioeconomic variables, it was observed that prevalence of obesity hypertension was dependent on each of gender variation, marital status, occupation, and utilization of time. But the study of association did not identify the most responsible variable for the prevalence. To identify one or more responsible variable(s) factor analysis [ 25 - 27] can be done where highest factor loading of a variable indicates the most responsible variable for the variation in the data set.

To perform the factor analysis the variables included were residence, religion, gender, marital status, age, education, occupation, family income , family expenditure, physical work, utilization of time, habit of taking restaurant and can food, duration of the disease, etc. The inclusion of these variables was satisfactory as $\mathrm{KMO}=0.640$ resulting $\chi^{2}=695.609$ with $\mathrm{p}$-value $=0.000$. During analysis some of the variables were dropped as their communalities were less than 0.40 [ 25 - 27] . For final analysis the included variables were all except religion, residence, education and habit of taking restaurant food. During fresh analysis the value of KMO was found 0.642 resulting $\chi^{2}=543.775$ with $\mathrm{p}$-value $=0.000$. The analytical results were shown in Table 3 .

Table 3. Results related to factor analysis

\begin{tabular}{|l|l|l|l|}
\hline Variable & Communality & Coefficient of factor -1 & Coefficient of factor -2 \\
\hline Gender & 0.694 & -0.130 & 0.823 \\
\hline Marital status & 0.561 & 0.794 & -0.013 \\
\hline Age & 0.601 & -0.761 & -0.146 \\
\hline Occupation & 0.793 & -0.172 & 0.873 \\
\hline Income & 0.500 & 0.507 & 0.494 \\
\hline Expenditure & 0.438 & 0.490 & 0.445 \\
\hline Utilization of time & 0.714 & -0.845 & -0.016 \\
\hline Accustomed with can food & 0.248 & -0.003 & 0.498 \\
\hline Physical work & 0.657 & 0.618 & -0.526 \\
\hline
\end{tabular}

Archives of Diabetes and Endocrine System V3 . I1 . 2020 
The results indicated that utilization of time was the most responsible variable for the prevalence of obesity hypertension in adult followed by marital status, age and physical work.

\section{Discussion}

Obesity is associated with hypertension, diabetes and cardiovascular diseases and it is the important risk factor for hypertension. This was observed in different studies in both home and abroad [ $1-3,29-33$ ]. The identified social determinants of hypertension were elderly male ; married, diabetic, and unemployed person; and member of lower income family [34].

Almost similar results were evident from the present analysis. Prevalence of obesity hypertension was more likely to develop in non-Muslims, females, illiterate persons, married persons, persons of ages 40 - 50 years, housewives, students and others, adults of highest income and expenditure group of families, physically inactive, adults involved in sedentary activities, and persons accustomed with restaurant food. This was observed from the results of odds ratio. But the study did not identify the more responsible determinants for prevalence of obesity hypertension. The important variables for this health hazard were detected by factor analysis. Sedentary activity like paper reading, viewing television and gossiping with friends and relatives over phone outside the normal duty was the most responsible factor for obesity hypertension followed by marital status, age, and physical inactivity.

\section{CONCLUSION}

The results presented in this paper were observed in analysing data recorded from 960 adults of ages 18 years and above. These adults were interviewed by some doctors and nurses from and nearby their working places in both urban and rural areas.

Percentages of rural and urban adults were 43.5 and 56.5, respectively and both the groups were similarly exposed to obesity hypertension. Females were $44.8 \%$ and they were $29 \%$ more exposed to this health problem. There were $27.5 \%$ adults of ages 40 - 50 years and obesity hypertension was 1.83 times likely to prevail in them. Marital status and obesity hypertension was significantly associated and married adults
(69.8\%) were 71\% more exposed to this health hazard. Though literacy was not significantly associated with this health problem, still illiterate adults ( $5.6 \%$ ) were $56 \%$ more exposed to this problem. Occupation and obesity hypertension were significantly associated and adults not directly involved in physical labour

( $34.5 \%$; housewives, students and unemployed) were $83 \%$ more exposed to this problem. Obesity hypertension was 1.37 times likely to develop in physically inactive adults compared to their counterpart. Family income and family expenditure were independent of this health hazard, but adults belonged to highest income and highest expenditure group of families had more chance to be affected by this problem.

Viewing television, reading paper and gossiping over phone outside normal working hours are sedentary activities and these activities were associated with obesity [ 35]. There were $34.7 \%$ adults who were involved in sedentary activities. Obesity hypertension was 4.56 times likely to develop among these group of adults as in adults of normal activities. Again, accustomed with restaurant food, junk food and smoking habit are components of unhealthy lifestyle. But, the present data did not signify any association between unhealthy lifestyle and prevalence of obesity hypertension. The chance of prevailing this health problem in adults accustomed with restaurant food was $50 \%$ more compared to that of other adults. Finally, factor analysis indicated that obesity hypertension was more prevalent among adults involved in sedentary activities, married persons and persons of ages 40-50 years and physically inactive labours.

Due to upward social mobility in respect of literacy, economic activities and increased mechanical movement,obesity and its related health hazard cannot be avoided[36]. But, there should be attempts to reduce the prevalence rate of the diseases related to obesity and hypertension. Success of the attempts depends on implementation of appropriate health plan by the Government. For this, people can be alerted against the health hazard prevails in the society due to non-communicable diseases and they can be motivated against this health problem. People can be encouragedto take active part in implementing the Government health program. Active participation by the people should be in the following aspects: 
(i) To encourage others in the society for taking healthy and homemade food,

(ii) To discourage others not to take junk food, more sugar-based food, salty and fatty food,

(iii) Everybody should be encouraged to avoid drugs , drinks an smoking,

(iv) Everybody should be encouraged to do some physical labour, physical exercise or at least try to walk whenever it is possible,

(v) Everybody should try to control the increase in body weight,

(vi) Whenever any health problem is felt, try to join the blood screening programme,

(vii) Patients of non-communicable diseases should consult the medical practitioner as a routine work.

Rural and urban health workers, social workers, and government health service providers can do a lot to encourage the people to follow the above steps. They can also provide free health service to general people to check at least blood pressure and blood sugar in a quarterly basis.

\section{REFERENCES}

[1] Krzysztof, N.( 2006): Obesity and hypertension - the issue is more complex than we thought, Nephrology Dialysis Transplantation, 21(2),264 - 267. https:// doi.org/10.1093/ndt/gfi290.

[2] Davy, K.P.; Hall, J.E.( 2004): Obesity and hypertension: two epidemics or one? Amer Jour Physiol Regular Integer Com Physiol , 286, R803 -813 . doi: 10.1152/ajpregu.00707.2003.

[3] Landsberg, L.; Molitch, M. (2004): Diabetes and hypertension : Pathogenesis, prevention, and treatment, ClinExpHypertens, 26, 621 - 628. doi: 10.1081/CEH-200031945.

[4] Bernard, M.V. and Chao, Li. ( 2012): Diabetes and hypertension : Is there a common metabolic pathway ? CurrAtheroscler. Rep, 14(2),160 166.

[5] Gress, T.W. ; Nieto, F.J.; Shahar, R. et al ( 2000): Hypertension and antihypertensive therapy as risk factors for type 2 diabetes mellitus, Atherosclerosis Risk Communities Study. N Engl J Med, 342, 905 - 912. doi: 10.1056/ NEJM 200003303421301.
[6] Mahler, R.J.( 1990): diabetes and hypertension, HormMetab Res. 22(12), 599 - 607.

[7] John, E. Hall.; Jussara M. do Carmo.; Alexandre, A. da Silva. ; Zhen Wang and Michael, E. Hall (2015): Obesity- Induced Hypertension: Interaction of Neurohumoral and Renal Mechanisms, Circulation Research , 116, 991 - 1006. https:// doi:org10.1161/CIRCRESAHA. 116.305697.

[8] Theodore, A.K.(2010): Obesity-related hypertension: Epidemiology, Pathophysiology, andClinical Management, Amer Jour Hypertension, 23(11),110 - 1178. https://doi. org/10.1038/ajh.2010.172.

[9] Dhurandhar, N.V.(2001): Contribution of pathogene in human obesity. Drug News \& Perspectives, 7(5), 307-313.

[10] Beg, C.; Rosengren, A.; Aives, N. et al (2005): Trendis in overweight and obesity from 1985 to 2002 in Goteberg, West Sweden, Inter. Jour. Obesity, 29(8), 916- 924.

[11] Skliros, E.A.; Merkoures, P.; Sotiropoulos, A. et al (2008): The relationship between body mass index and hypertension in elderly Greeks: the Nemea Primary Care Study, Jour. Amer. Geriatrics Society, 56(5), $954-955$.

[12] WHO (2020): Fact Sheets/Detail/Obesity and Overweight, March 2020.

[13] Fardus,J. and Bhuyan, K.C. (2016): Discriminating diabetic patients of some rural and urban areas of Bangladesh: A discriminant analysis approach, Euromediterrean Bio.Jour.11(9), 134 - 140.

[14] Hall, J.E. and Louis, K. ( 1994): Dahl Memorial Lecture: Renal and Cardiovascular Mechanisms of Hypertension in Obesity, Hypertension,23, $381-394$.

[15] Ribstein, J. ; Guilhem du Cailor. and Mimran, A.(1995): A combined renal effect of overweight and hypertension, Hypertension, 26, 610 - 615.

[16] Monteiro, C.A. ; Moura, E.C. ; Condel. W.L. and Popkin, B.M. (2004): Socioeconomic status and obesity in adult populations of developing countries, Bull WHO, 82, 940 - 946.

[17] Bhuiyan,D. and Bhuyan,K.C.(2019): Discriminating Bangladeshi adults by noncommunicable diseases, Rehabilitation Science,4(3), $35-43$. 
[18] Akter,S.;Rahaman, M.M.;Sarah, K.A.;and Sultan, P.(2014): Prevalence of diabetes and pre-diabetes and their risk factors among Bangladeshi adults: A Nationwide survey, Bulletin of the WHO, 92,204 - 213 A.

[19] Mokdad, A.H.; Ford,E.S.; Bowman,B.A.; Dietz, W.H.; Vinicor,F.; Bales,V.S. et al ( 2003): Prevalence of obesity, diabetes, and obesity-related health risk factors 2001, JAMA, 289,76- 79.

[20] Saquib, N.; Saquib, J.; Ahmed,T; Khanam,M.A.;Cullen,M.R.(2012): Cardiovascular diseases and type II diabetes in Bangladesh: a systematic review ant meta- analysis of studies between 1995 - 2010, BMC Public Health, 12, 434.

[21] Dinsa, G.D.; Goryakin, Y. ; Fumagalli, E. and Suhrcke, M.( 2012): Obesity and socioeconomic status in developing countries: A systematic review, Obesity Reviews , 13(11), 1067-79,. Doi:10.1111/j.1467-789X.2012.0101.x.

[22] Cheung, B.M.(2010): The hypertension - diabetes continuum, J. Cardiovasc. Pharmacol, 55, 333 - 339.

[23] Hall, J.E. ( 2000): Pathophysiology of obesity hypertension, Curr Hypertension Rep. 2, 139 147, doi:10.1007/s 11906-000-0073-4.

[24] Bhuyan,K.C. and Fardus,J. ( 2019): Level of obesity and socioeconomic factors of a group of adult people of Bangladesh: A factor analysis approach, Amer, Jour. Data Mining and Knowledge Discovery, 4(1), 8-14, doi: 10.11648/j. ajdmkd.20190401.12.

[25] Bhuyan, K.C. (2019): A note on factor analysis applied in medical research, Archives in Biomed Eng. And Biotech. 1(4), 1-3.

[26] Yotoka,T.(1983): Some criteria for variable selection in factor analysis, Behaviormetrika,13,31 -45.

[27] Rusico, J. and Roche, B.( 2012): Determining the number of factors to retain in an exploratory factor analysis using comparison data of known factorial structure, Psychological Assessment, 24(2), 282 - 292,doi:10.1037/a 0025697.
[28] Syed, M.S.; Debra, N.;Muhammad, H.R.; Musa, R; AND Gul, N.( (2004): Assessing obesity and overweight in a high mountain Pakistani population, Tropical Medicine and International Health,9(4), 526-532.

[29] Coatmellec- Taglioni, G. and Ribiere, C.(2003): Factor that influence the risk of hypertension in obese individuals, CurrOpinNephrolHypertens, 12(3), $305-308$.

[30] Kotsis, V.; Stabonli, S.; Bouldin, M.; Low, A.; Toumanidis, S. and Zakopouls, N.( 2005): Impact of obesity on 24-hour ambulatory blood pressure and hypertension, 45, 602 - 607. doi:10.1161/01. HYP.0000158261.86674.8e.

[31] Shu-Kang Wang.; Wei, Ma.; Shumei, Wang.; XiangRen, Ti.; Hong Ying Jia; and FuzhongXue (2014): Obesity and its relationship with hypertension among adults 50 years and older in Jinan, China, PLOS ONE.https://doi.org/10.1371/journal. pone.0114424.

[32] WHO (2001): Prevalence, awareness, treatment and control of hypertension among elderly in Bangladesh and India,: a multicentre study.

[33] Narkiewicz, K.(2002): Obesity - related hypertension : relevance of vascular reponses to mental stress, J.Hypertens, 20, 1277- 1278.

[34] Eyito,0.0.; Daniel, T.G.; Oladele, V.A. and Eunice, S. (2016): Social epidemiology of hypertension in Buffalo City Metropolitan Municipality ; Crosssectional study of determinant of prevalence , awareness , treatment, and control among South African adults, BMJ, https://dx.doi.org/10.1136/ bmjopen-2016-014349.

[35] Crawford, D.A. ; Jeffry, R.W. and French, S.A.( 1999): Television viewing, physical inactivity and obesity, Int. J. Obes. Relat.Metab.Disord. , 23, 437 - 440.doi: 10.1038/sj.ijo.0800845.

[36] [ Bhuyan, K.C. ( 2020): Socioeconomic variables responsible for diabetic retinopathy among Bangladeshi adults, BJSTR, 25(1), 18829 - 18836. Doi: 10.26717/BJSTR.2020.25.004150.

Citation: K.C.Bhuyan. Identification of Responsible Variables for Obesity Hypertension among Bangladeshi Adults. Archives of Diabetes and Endocrine System. 2020; 3(1): 27-34.

Copyright: (C) 2020 K.C.Bhuyan. This is an open access article distributed under the Creative Commons Attribution License, which permits unrestricted use, distribution, and reproduction in any medium, provided the original work is properly cited. 